\title{
Cuento
}

\section{LA OSCURIDAD PERSEGUIDA}

The chased darkness

\section{Gonzalo Portals-Zubiate ${ }^{1}$}

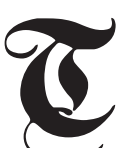
odavía recuerdo el día que esperé por ella en el restaurante. ¿Fue angustia lo que sentí aquella vez o solo un sobresalto difícil de apaciguar al imaginar, casi secretamente, que dicho encuentro me arrastraría a un cúmulo de episodios nunca antes experimentados? Mi vida, por ese entonces, era una especie de úlcera hiriente. Las cosas a mi alrededor habían cambiado sobremanera. Yo, siendo el mismo en esencia, había cambiado, me había transformado en alguien más ajeno y bastante menos hospitalario de cuerpo y espíritu, al punto que me resultaba casi inadmisible relacionarme con alguien que no fuera mi propio ser. Así que la posibilidad de compartir mi vida con alguien e incluso de solamente conocer a alguien no abría necesariamente en mí un espacio de reposo y tranquilidad. Recuerdo que ella llegó con un breve retraso. No la culpé, solo me interesaba verla, dialogar y compartir un almuerzo agradable. $Y$ si ya antes de su arribo había estado haciendo de las servilletas unos pequeños cuadrados que luego dejaba tranquilamente sobre la mesa, con ella sentada a mi lado, mi desajuste inicial no se disolvió sino hasta algunos minutos después y solo gracias a la energía que ella me regaló y supo

1 Poeta y narrador. Ganador del XXIII Premio Concurso de Novela Corta «Julio Ramón Ribeyro» 2020 del Banco Central de Reserva del Perú.

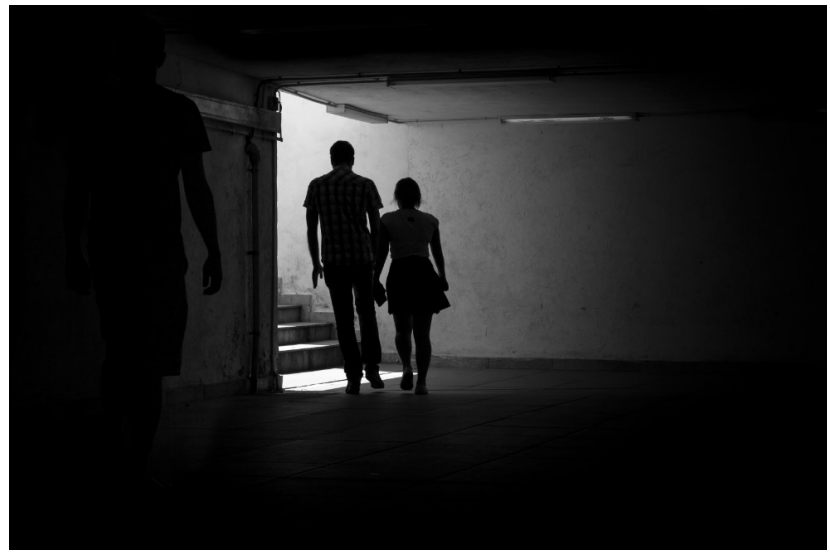

Pareja en la noche. Fotografía en B/N. https://wallhere.com/es/ wallpaper/ 878819

inocularme. Anticiparnos a lo que vendría luego fue como ingresar, con un pensamiento inflexible, en un jardín de piedras verdosas y mausoleos sorpresivos.

Esta noche, algunos meses después de ese primer encuentro y concretada nuestra relación, estoy en nuestro cuarto y aguardo por ella. Es un miércoles cenizo; parece que un volcán hubiera disipado su carga oscura sobre la ciudad. El invierno lo inunda todo, torna las pistas y las calzadas sombrías y resbaladizas. A veces me asomo a nuestro balcón y presiento que esta es otra época, tal vez la de unos cuantos siglos atrás, una época menos dura, más perdurable. E incluso me animo a pensar que se trata de otra ciudad y otro país, y que sus edificios o monumentos que se divisan 
o intuyen de forma nebulosa podrían pasar tranquilamente por otros. ¡Cuánta ingenuidad de mi parte, cuánto engaño inmerecido! Pensar que este espacio podría ser cualquier otro es un artificio de la mente para escamotear mis miedos y no desear, por comodidad o inercia, otros destinos y nuevas aventuras. Este lugar donde nos ha tocado en suerte vivir, me digo, debe responder también al concepto de ciudad imaginada, de urbe sometida al espejismo de quienes la soñamos de manera distinta a lo que en realidad es o tendría que ser. La lluvia menuda y la humedad son mis defensas más sólidas contra la claridad que todo lo evidencia. Prefiero esto, lo de ahora, esto que no define ni objetiva, y que más bien, configurándolo apenas con una bocanada de aire o un espiral de frío, engaña los sentidos y hace pasar una cosa por otra muy distinta.

Cuando ella estuvo de vuelta en el cuarto, con su cabello atrapado por una toalla naranja y su cuello y hombros humedecidos por el agua de la ducha, lo encontró contemplando la calle como quien espera por algo que no llega o que acaba de ver a alguien arrastrándose lastimosamente por el pavimento para, tras unos minutos de agonía de inverosímil, dejarse vencer bajo un poste de alumbrado público.

- Te veo pensativo -le dijo, como siempre que buscaba iniciar una charla. -¿Qué dice la gente de afuera? -bromeó.

No había gente afuera, solo lluvia fina y sombras confidentes. Ella dio unos pasos alrededor del cuarto, como quien reconoce un reducto personal, y se dejó caer en el sillón. Una toalla de tonos encendidos le cubría el cuerpo por debajo de los senos. Había recogido las piernas, y él, desde un punto de vista lateral, casi como un anciano lascivo y fisgón con respecto a su ubicación, alcanzaba a destacar parte de su cuerpo, sus facciones algo alargadas y su ensimismamiento característico, una especie de armazón femenino del que solía premunirse con frecuencia y que resultaba difícil vulnerar. No obstante, porfió una vez más su silencio:

- ¿Te parece si vamos a caminar un rato? -le planteó abiertamente.

No encontró respuesta. Vio su rostro afilado, una mezcla de rigidez y sensualidad impracticables. Su pareja parecía estar inmersa en una serie de cavilaciones. Un minuto después volvió a insistir, pero esta vez con otra fórmula.

- Pienso que podríamos aprovechar estas circunstancias especiales y salir un momento a pasear. ¿Qué te parece? ¿Te animas?

La mujer alzó el rostro de su teléfono móvil.

- ¿Quieres salir, salir ahora? -le dijo, con un inobjetable gesto de desaprobación.

Hay ciertas claves aprendidas y otras estrategias de convencimiento que se van asimilando y utilizando en el extenso y sugerente camino de las relaciones de pareja. Uno de estos ardides tiene que ver con el hecho fundamental de no ejercer presión. El poder del convencimiento no estriba necesariamente en la cantidad de veces que se dice o pide algo o en el énfasis que se le atribuye a las palabras empleadas en dicho pedido, sino en aquello que uno se reserva para sí mismo, que no dice abiertamente pero que termina flotando en el ambiente como una disuasión o un refuerzo implícito. Sea como fuere, la noche cerrada los halló caminando desde el epicentro mismo de la ciudad hacia los barrios acomodados del sur. ¿Adónde pensaban ir con esta neblina y esta lluvia incipiente que los hacía ver como espectros en una urbe desolada? ¿Hasta dónde 
pretendían caminar? ¿Hasta que las fuerzas se lo permitieran y les obligaran a dar media vuelta y retornar apurados a desfallecer en su cama, para luego de esa travesía sin sentido entregarse al amor inclaudicable? Tal vez ninguno de los dos lo sabía con exactitud, ninguno de los dos se animaba a esbozar una respuesta.

- ¿Has dejado tus cosas de valor, verdad?

- le preguntó ella al salir. Y aunque él le contestó afirmativamente, asegurándole que solamente traía las llaves consigo, ella, fiel a su nerviosismo y ansiedad, le palpó los bolsillos. Convencida al fin, se hizo a un lado para que él pudiera cerrar la puerta.

- Bien, vamos ya -le dijo.

En el descanso de la escalera, donde una luz clarividente le otorgaba al descanso del piso una dulzura amigable, él alcanzó a destacar en ella un bolso y, sobresaliendo de éste, como el ápice hiriente de un arma arrojadiza, un libro cuya portada creyó reconocer.

- ¡Vaya! -exclamó. -¿Lista para continuar con tu lectura?

- Sí - dijo ella.

Abandonaron el edificio y se pusieron en marcha con pasos cortos, medidos, como quien tienta una ciudad por primera vez. Al inicio, ésta se presentó amplia, como un enorme panal del que parecía fluir una diversidad de luces minúsculas. Se asemejaba a una entidad viva, aunque sin gente, a cuyo centro, que era donde ellos se hallaban, se concentraban todas las vertientes, todas las miradas.

- Tengo miedo -le dijo ella de pronto. -Creo que no debimos salir.
Eso lo dijo a los pocos minutos de iniciada la marcha. Pero luego, cuando llegaron a la plaza, y especialmente cuando dieron con la desembocadura de ésta y empezaron a adentrarse en la extensa avenida, con sus bloques de casas de tonos ocres y sus edificios sumidos en un sueño de desarraigo y abandono, la mujer se fue haciendo a la ciudad, se fue dejando tragar y consumir por su energía. Y es que no solo la fisonomía del lugar había empezado a variar ostensiblemente, sino también la relación con ellos en su calidad de transeúntes improbables. Ahora se percibían menos desamparados, como acorazados por un impermeable alzado del mismo lugar $\mathrm{y}$, por lo tanto, más seguros y dueños de sí mismos.

- ¿Qué haremos si la policía nos encuentra?

- le habló ella de manera imprevista.

- Mentir. Diremos que nos amamos, que un día como hoy comenzó nuestra relación, hace ya dos años de eso, y que por esa razón decidimos dar un paseo por nuestra ciudad para celebrar.

Ella lo miró, o al menos eso creyó él, con un gesto que denunciaba algo de fastidio o incomprensión ante sus desvaríos.

- Eso no es cierto -le refutó ella al rato.

- ¿Cuál de las cosas que te he dicho recién?

¿Que no te ame o cuál otra?

Por encima de sus sombras, la berma central de la avenida, con sus árboles centenarios y frondosos parecía el ingreso a la nave central de una iglesia en ruinas.

- ¿Recuerdas la vez que viajamos al sur? 
¿Cuando visitamos tres o cuatro ciudades que no conocías? ¿Y recuerdas esa iglesia parcialmente destruida por el terremoto? ¿Cuando paseamos entre sus ruinas e ingresamos a ese sótano que parecía algo así como una cripta? ¿De qué siglo era? Creo que lo dijo el guía. ¿Te acuerdas de eso?

Ella no respondió. Solo siguió caminando a su lado, entre precavida, temerosa y poco dispuesta a la aventura. Siempre era difícil generar en ella un espacio para el sobresalto. O tal vez él, en todo este tiempo de relación aún no había dado con las claves, esa especie de gran llavero conformado por piezas maestras, algunas visibles y otras no tan tanto, que propician el acercamiento o facilitan el encendido permanente de la dicha. Pasaron delante de un restaurante de comida rápida, cuya puerta clausurada no les llamó la atención si no hubiera sido por la aparición repentina de un sujeto que estaba de pie bajo el anuncio apagado. En un primer acercamiento, a ambos les pareció parte del decorado, una pieza descolorida de la fachada del lugar, pero luego, cuando ladeó la cabeza hacia ellos y entornó los ojos con una mezcla de desencanto y pavor, si es que se puede conciliar ambos sentimientos en una sola mueca, se percataron de que se trataba de alguien real. Los vio, alargó su mano nervuda, les pidió algo que ellos prefirieron no entender, y volvió a refugiarse tras una mampara.

- Ahora sí tengo miedo, de verdad -reveló ella con más intensidad.

¿Qué hora sería ya? La ciudad era de una negrura insípida. Probablemente las dos de la mañana o un poco menos. Desde que salieron de su habitación en el centro, no habían visto un solo policía, apenas una mujer cargada de plásticos y cartones hallados en los tachos de basura. Pero nada más. La ciudad tenía el aspecto de una gran carpa de circo abandonada a su suerte, pero no uno de esos espectáculos majestuosos que suelen arribar a las grandes ciudades con sus números de trapecistas, osos amaestrados y acróbatas de enorme gracia y talento, sino de uno de aquellos instalados en los barrios marginales, en los lugares alejados de la mano de un dios menor, ahí donde la farsa se eleva desde el suelo y queda suspendida en el aire para dar lugar a un espectáculo triste, de falsedad enfermiza, con adivinos y bailarines falseados, y donde incluso al maestro de ceremonias, si lo hay, se le escucha destemplado por la mala noche y el abuso de alcohol.

- Deberíamos sentarnos a leer -le propuso él.

- ¿Dónde?

Él creyó intuir en su pareja una chispa imprevista de interés.

- No lo sé. ¿Aquí? ¿Qué te parece aquí mismo?

La luz era algo baja, parecía una luz flagelada por un espíritu codicioso, pero se sentaron delante de un edificio, en un parapeto de cemento, a cuya espalda se alzaba una pequeña pared de arbustos.

- ¿Estás bien? -preguntó él.

- Sí.

Leyó: "Sentía la necesidad de comenzar a vivir. ¿Comenzar a vivir mi verdadera vida? Incluso en el caso de que se tratara de una pura mascarada y no de mi vida, realmente había llegado el momento en que debía ponerme en marcha, avanzar arrastrando mis pesados pies". 
Había tomado el libro entre sus manos, liberado el marcador, y leído el pequeño párrafo como quien se hace o le hace una confesión inopinada. Luego, al cabo de unos segundos, lo cerró y se quedó en silencio.

- ¿Pasa algo? -le preguntó él, aunque sabía casi con exactitud cuál era ese sentimiento tan fuerte que la invadía. Había subrayado esas pocas líneas del libro de Mishima por una razón específica; su elección, qué duda cabe, no era gratuita.

- Tengo hambre -le dijo de improviso.

- ¿Sí?

- Sí, pero como de algo distinto, desconocido, ¿me entiendes?, una comida que no hayamos probado hasta ahora, una cosa extraña, fuera de este mundo.

La semioscuridad del lugar, si bien amparaba y velaba sus gestos, propiciaba que sus emociones fluyeran con una liviandad distinta, menos custodiada por las cortapisas impuestas por los espacios cerrados. Y era extraño que una cosa así ocurriera. Los dos habían desembocado de manera casi natural en ese lugar, casi como dos invidentes guiados por un principio de orientación común, emanado ya no de cada ser individual sino de ambos, como si se tratara de una sola entidad $\mathrm{y}$, desde luego, de una única necesidad de avanzar a través de esa ciudad enferma y tenebrosa. ¿Pero por qué no habían prefigurado esta escena en el cuarto, por qué no lo habían hablado en ese lugar y liberado ahí sus confesiones largamente encriptadas? ¿Será que su recinto de siempre ya no funcionaba para ello y, por ende, había perdido sus cualidades intimistas, indispensables para sacar a flote aquellas palabras usualmente negadas a salir, reducidas generalmente a un bolo en la garganta, de esos que conforman frases que, sin posibilidades de escapar, optan por quedar atrapadas y morir dentro de uno?

- ¿Qué te dice Koo-chan? -quiso saber él.

- ¿A qué te refieres?

Ella parecía algo estremecida por el frío de la madrugada, un frío serpenteante que daba la sensación de asentarse en su cuerpo, envolviéndolo con aprensión, y luego seguir su curso hacia el ámbito de donde habían salido, la zona más rígida de la ciudad.

- El protagonista de Confesiones de una máscara, claro -le dijo él. -El joven y dolido Yukio Mishima en su afán por inscribirse en otra fisonomía, en una nueva identidad, en alguien distinto, en otro ser.

Ella guardó silencio. Se había envuelto en su abrigo negro, del que sacaba de tanto en tanto su mano derecha para continuar con la revisión del libro. Ahora, abierto de par en par, el texto mostraba algunas partes resaltadas con una tinta amarilla que la oscuridad reinante no pudo escamotear. Leyó una vez más:

"La belleza de la ciudad era, ni más ni menos, la belleza de sus heridas". Esto me gusta mucho -dijo. -Entiendo que lo que quiere decir con esta frase es que nosotros también somos la ciudad en la que nos movemos. Y todo aquello que incide sobre la ciudad en la que vivimos, incide también en nosotros. ¿Tú qué opinas?

- Recuerdo ese libro -le confesó él, con un ojo en la página abierta. -Lo leí hace mucho tiempo y todavía algunas de sus frases y párrafos resuenan en mí.

- Ya veo -reveló ella, inconforme. 
- Desde luego que eran situaciones muy distintas a las actuales. En ese entonces yo era un tipo joven que deseaba otras cosas, que vivía de otra manera y me comportaba de un modo distinto al actual. Era, si vale decirlo, más categórico y bastante más rígido conmigo mismo. Ese libro apareció en mi vida en un momento crucial, de muchas definiciones. Y, por supuesto, la novela generó en mí una especie de inflexión, un punto de quiebre.

- Supongo que sí -consideró ella. -Debe ser de esos libros que no se olvidan nunca y que desencadenan en nuestras vidas un importante vuelco de timón. Uno de esos textos a los que siempre se regresa; y más de una vez.

- Sí -consintió él-, aunque las razones para recordarlo han sido muy diversas para mi experiencia de vida. Y de seguro son y serán otras las razones por las cuales tú, pasado el tiempo, volverás de nuevo a él.

Ella se quedó como ensoñada, mirándolo. Un aura mortecina encuadraba caprichosamente el rostro del hombre, haciéndolo ver bastante más maduro de lo que ya era, con un abatimiento en los ojos que a ella le provocó una mezcla de ternura y angustia irreprimibles.

- Siento que el protagonista de la novela quiere vivir su vida a plenitud -señaló ella.

- Ha pasado mucho tiempo aprisionado, obligado a ser quien no es, metido dentro de un cuerpo y una identidad que realmente no le pertenecen. La pintura del muchacho flagelado por dardos... ¿La recuerdas? ¿Cómo es que se llama?

- El San Sebastián, sí... De Guido Reni, ese es el nombre del artista.
Transcurrieron unos segundos en los que ella dio la impresión de buscar en su memoria otros detalles ocultos del cuadro.

- Sí, ese mismo -dijo luego. -Pero creo que más allá de la identificación con el martirio del santo, el protagonista de la obra de Mishima se siente otro a partir de la experiencia tremenda del dolor. Es decir, después de contemplar esa pintura, confirma que su propio dolor, por más intenso que haya sido, fue necesario para cambiar de piel, para dar a conocer su verdadero rostro.

- Lo entiendo -le confesó él.

En ese momento, un cono de luz se destacó por la boca de una de las calles adyacentes, que los hizo sobresaltarse.

- ¿La policía, es la policía? -quiso saber ella, algo exaltada.

Un automóvil no identificado atravesó la avenida y se perdió lentamente, sumido en su propia luz interior.

- Creo que debemos regresar -consideró.

Él intentó apaciguarla.

- Antes busquemos algo para comer, ¿sí?

- ¿Dónde? No creo que haya un lugar abierto a esta hora.

- ¿Tú crees que nosotros somos los únicos sujetos en arriesgarnos? -contestó él y la miró, esperando una respuesta que no llegó.

- Ven -añadió-, busquemos alguna cosa por ahí. 
Y se pusieron en marcha: ella, un par de pasos por delante, algo apurada y decidida, como si alguien atizara sus movimientos desde atrás o la convocara desde un horizonte lejano; y él, sereno, casi cansino, observando desde su posición de qué modo esa ciudad sin nombre la iba engullendo de manera impía. A esa hora ya no oscurecía más; los colores se habían atrincherado en sus reductos, conformando bloques, meandros $\mathrm{u}$ hondonadas donde los ojos, si miraban en demasía, hacían del naufragio de la vida una realidad abrumadora. La berma central de la avenida, enclaustrada entre sus árboles viejísimos, le hacía pensar a él en la nave de una iglesia sumergida en el océano y recordar el poema sinfónico de Debussy, tan callado, tan diáfano y veraz. A ella, en cambio, le traía a la mente una serie de recuerdos dolorosos de su infancia, episodios plagados de abismos y negrura que resultaba necesario exorcizar aunque su ingreso en estos le generara un pavor todavía más hiriente. Caminaron unas cuadras más en dirección a las brumas y la cabecera de las playas en una especie de descenso a un territorio inexplorado. Ni siquiera él, que antes de conocerla, había vivido en esta parte de la ciudad a la que ahora arribaban, podía dar cuenta del cambio experimentado.

- ¿Qué pasa? -le preguntó ella, bajando la intensidad de su caminata e igualando el ritmo de su pareja.

- Ya no reconozco nada de esto -le dijo él, con un sentimiento cercano a la apatía. -Es decir, la ciudad sigue siendo, en esencia, la misma de siempre, la que yo conocí de pequeño y recorrí en mi juventud. Pero ya no me reconozco en ella; por más esfuerzo que esté en capacidad de hacer, ya no me veo ni siento parte de este lugar. Soy un extraño.
Ella le echó una mirada de pena y continuó caminando por entre el armazón de ramajes y sombras enervantes. Desde su ubicación a la zaga la vio, una vez más, escabullírsele de su espacio más íntimo en pos de algo que parecía hallarse más allá de lo que él parecía capaz de ofrecerle. Mirarla, como lo estaba haciendo en este momento, era detenerse de manera demudada en un futuro ilusorio, en un ideal armado improvisadamente sobre unas estructuras tan cuestionadas como endebles. Porque, y esto era algo que se lo preguntaba con una frecuencia inusitada, ¿quién era ella, a fin de cuentas? Y, sobre todo, ¿qué representaba para él alguien como ella en un momento como este en el que prácticamente había cedido todo fervor, toda energía juvenil en beneficio de una llaneza, una parquedad, una calma semejante al abandono? Entonces, ¿de qué modo podía equiparar el brío y la juventud de esa mujer tan joven, casi una adolescente, si la conducta de él se aproximaba más a la pasividad y a veces incluso a la renuncia?

- Siento que yo, como el personaje de la novela de Mishima, he vivido de espaldas a aquello que siempre quise hacer o que por mi juventud e inexperiencia tendría que estar haciendo ahora mismo. Y eso me pone mal.

La tenía a un palmo de distancia, casi tan cerca como para enlazarle el talle con su brazo o tomarla de la mano como a una pareja convencional. Pero prefería este distanciamiento, una separación que desde que se conocieron había sido una cláusula entre los dos, una suerte de contrato establecido de manera no verbal pero que respondía a su condición particular de pareja. Ello era algo así como un rastrearse, un ejercicio de calma y codicia pendular, un verse y desearse, mirarse y tantear, pero sin concretar, por lo menos no hasta que estuvieran de regreso en 
su habitación. Allá, como siempre ocurría, enajenados por los claroscuros del lugar, aparecerían apenas destacados por las luces macilentas del exterior, cauterizados por los ruidos circundantes, en un reducto indefinido por la oscuridad perseguida, en un espacio de privilegio donde todo se tornaba factible y las diferencias de edad o las limitaciones físicas se travestían o aligeraban de importancia.

- Intento comprender -le habló él de forma apaciguada.

- Si el protagonista de Confesiones de una máscara -añadió ella con prontitud, como si no deseara perder las palabras de las que venía haciendo acopio para ofrecerle a su pareja una respuesta más o menos convincente- sabe que con sus acciones o su forma de ver y experimentar el mundo no está respondiendo a su verdadera índole y se siente dolido o insatisfecho por ello, conmigo sucede algo parecido.

Había bancas disponibles en el camino, sembradas en los bordes de la berma central como si fueran maceteros sin flores. Tal vez había sujetos inertes sentados en ellas, hablándoles a la Luna o celebrando la aparición repentina de una botella de licor barato o un café caliente entre las manos. Ninguno de los dos, en todo caso, las vio o quiso verlas cuando pasó entre ellas. Prefirieron circular como dos barcazas, cuyos derroteros habían sido prefigurados desde antes de esta experiencia, ella por delante, él siguiéndole los pasos. De tanto en tanto, algo semejante a un lamento, una fruta o un resquemor se descolgaba de los altos árboles de la ruta; les alargaban sus ramas enclenques, pero como ellos nada hacían o decían, describían unas maromas inverosímiles, se avecindaban con las negruras del entorno o se internaban profundo en esa tierra que, qué duda cabe, también era el cielo o un adelanto del mismo.

- Te escucho -le dijo él de pronto, a sabiendas de que adivinaba cuáles eran sus preocupaciones y qué era aquello que deseaba relatarle. -¿Qué es exactamente lo que tienes que decirme?

Tras describir una pirueta, que a él le pareció grácil aunque algo forzada, la joven fue a sentarse en el respaldar de una banca. Pese a que parecía dominada por una energía imprevista, a los pocos minutos colocó sus brazos y piernas pegados al cuerpo, como si quisiera evitar el ingreso indiscriminado del frío.

- ¡Diablos! -se quejó de pronto y puso su vista en el frente, los ojos muy abiertos.

- ¿Qué es? -quiso saber él. -Qué te ocurre? Dime...

- ¡Diablos! -volvió a lamentarse. -No puedo creerlo, de verdad no puedo creerlo.

Su rostro lucía descompuesto, zarandeado por una fuerza inusual.

- El libro -dijo al fin. -No está. Lo olvidé allá, en ese lugar -y señaló con el rostro la boca de negrura que, cerrada, descansaba a sus espaldas.

Entonces, no les quedó más remedio que desandar juntos el camino de regreso, ella otra vez por delante, él a la zaga, solo que esta vez más aprisa. Caminaron en silencio, casi dominados por una aureola de tranquilo desasosiego, pero era evidente que algo había cambiado. La ciudad ya no los contenía; en esta ocasión era un túnel oleaginoso por el que 
se deslizaban sus figuras sin dificultad. Los árboles se apartaban serenos a su paso, en tanto que un rumor de aguas tumultuosas parecía correr bajo el asfalto de las pistas adyacentes.

- ¿Aquí fue? -preguntó él, cuando, ante un muro custodiado por setos sin podar y paredes llenas de inscripciones, creyó dar con el sitio de hace unos momentos.

- ¡No! -se irritó ella. -Es más arriba.

Dos o tres cuadras más allá, la mujer se apartó de la berma central y encaminó hacia la avenida que tenía al frente, con los postes de alumbrado al mínimo de su luminosidad y sumida en un letargo cóncavo. Unos segundos después, él se le unió.

- No está -le dijo ella, con una pena cercana a la desolación.

El hombre miró hacia los lados y buscó en la parada de autobuses que tenía al lado y en la que el plástico protector del anuncio publicitario había sido retirado con violencia y sus luces destruidas. Luego se detuvo ante el muro de cemento y se afanó en una búsqueda infructuosa entre los arbustos.

- No hay nada. No lo veo por ninguna parte -le dijo.

Ella, visiblemente afligida, se había sentado en un poyo, probablemente el mismo donde extraviaron el libro, y porfiaba por un encendedor. Necesito fumar -le hizo ver a su pareja, con un cigarro entre los labios. Él le habló con indulgencia.

- Compraremos otro, ya lo verás. No te preocupes.
- ¿La misma edición? -replicó ella, los ojos encendidos.

- Ojalá.

- Esa era muy buena.

- Sí, lo sé. Lo buscaremos. Y si no lo encontramos acá, lo mandaremos pedir del extranjero. ¿Está bien? ¿De acuerdo?

Halló el encendedor que buscaba y se puso a fumar con ansiedad. Él, de pie y muy próximo a su pareja, la contemplaba con curiosidad y paciencia.

- Me siento atrapada -le dijo al fin, aparentemente más sosegada.

- ¿Lo dices por esta ciudad? ¿Por nuestra habitación? ¿Por lo nuestro? ¿Por la situación que estamos viviendo actualmente? ¿Es eso?

Dio dos pitadas apuradas y se volvió a mirarlo.

- No deseo enfermarme. Soy muy joven para ello. Quién lo quiere. Tal vez quizá tú, que eres un hombre que ya ha vivido demasiado y a quien no le importaría morir en este momento. Pero yo no. ¿Me entiendes?

Él le lanzó una mirada al edificio de departamentos que se levantaba justo frente a ellos. Lo conocía de vista porque había transitado infinidad de veces dicha avenida. Es solo que a esta hora, su habitual color verde apagado se percibía grave, un color sedentario, como la piel de un lagarto adormilado.

- Soy muy joven -le dijo casi con pesadumbre.

- Y deseo vivir la vida de alguien de mi edad. 
- Te entiendo -le contestó él, aún de pie, como quien aguarda una mala noticia o un comentario largamente esperado.

- Por ejemplo, conocer a otras personas -añadió. -Salir, divertirme, responder a mis verdaderos deseos e inclinaciones. Estos días de encierro forzado...

- ¿Qué hay con ellos? -se inquietó él.

- Ambos hemos estado obligados a vivirlos gracias a esta situación. Sé que ha sido algo que ha estado más allá de nosotros. Y hemos tenido que sujetarnos a las disposiciones generales. Digo, no había otra alternativa.

Él mostró su incomodidad e impaciencia describiendo un semicírculo nervioso alrededor de ella.

- Sí, sé lo que piensas -continuó ella. -Pude haber ido con mis padres, como otras veces que intenté hacerlo, pero no quise. Preferí quedarme contigo porque esto es lo que deseo; me reafirmo en ello. Pero esta ha sido y sigue siendo una prueba muy grande para mí... Y es que también quiero lo otro. Me siento como el personaje de la novela de Mishima -y volvió a mirar entre los arbustos a ver si la suerte le sonreía esta vez y hallaba el libro extraviado-, siento que no estoy actuando como tendría que ser a mi edad, que podría estar en una situación distinta y que lamentablemente no estoy siendo yo misma. Este encierro demasiado largo me ha hecho ver una realidad que no deseo para mí.
- Este encierro, lo sabes, es antinatural -dijo él, sin alterarse. -Nuestra vida no tendría necesariamente que ser así, no va a ser así.

Ella no buscó el apoyo de una imagen a su alrededor ni nada que pudiera revelarle otro ánimo, otro fervor, un giro novedoso, una suerte distinta. Solo se dejó estar; parecía apaciguada, abandonada a la idea inminente de una nueva pérdida.

- Me resulta imposible imaginar un futuro a largo plazo contigo -le dijo finalmente, en una frase que más que dura o cruel, a él le sonó auténtica y realista. Y diciendo eso, se puso de pie y lo tomó de la cintura, acercándolo a su rostro. -Amor, ¿saldremos un día de estos a comprar otro igual, verdad?

- le susurró al oído. -¿Lo haremos, sí?

- Por supuesto -le respondió él, esbozando una sonrisa discreta, para luego contenerla amablemente entre sus brazos. Confinados una vez más a su condición de pareja, volvieron a ponerse en marcha, esta vez uno al lado del otro. La ciudad despertaba ya y con seguridad su suerte no iría a durarles mucho tiempo más.

\section{CorRespondencia}

Gonzalo Portals Zubiate

literaturayenfermedad@gmail.com

FECHA DE RECEPCIÓN: 05-06-2020.

FECHA DE ACEPTACIÓN: 11-01-2021. 